"This is the peer reviewed version of the following article: Murray Parahi, P. , DiGiacomo, M. , Jackson, D. and Davidson, P. M. (2016), New graduate registered nurse transition into primary health care roles: an integrative literature review. J Clin Nurs, 25: 3084-3101., which has been published in final form at https://doi-org.ezproxy. lib.uts.edu.au/10.1111/jocn.13297. This article may be used for non-commercial purposes in accordance with Wiley Terms and Conditions for Self-Archiving." 


\title{
New graduate registered nurse transition into Primary Health Care roles: An integrative literature review.
}

\author{
Authors: Pauline Murray-Parahi ${ }^{1,2,3^{*}}$, Michelle DiGiacomo ${ }^{1,3}$, Debra Jackson ${ }^{1,4}$, Patricia M. \\ $1,3,5$ \\ Davidson
}

Affiliations:

$1 \quad$ University of Technology Sydney, NSW 2007, Australia

2 Liverpool Hospital, South Western Sydney Local Health District, Liverpool, NSW 2170 Australia

3 Centre for Cardiac and Chronic Care, Faculty of Nursing, Midwifery \& Health, University of Technology Sydney

4 Oxford Brookes University, Oxford, UK

5 Johns Hopkins School of Nursing, Baltimore Maryland 21205, USA

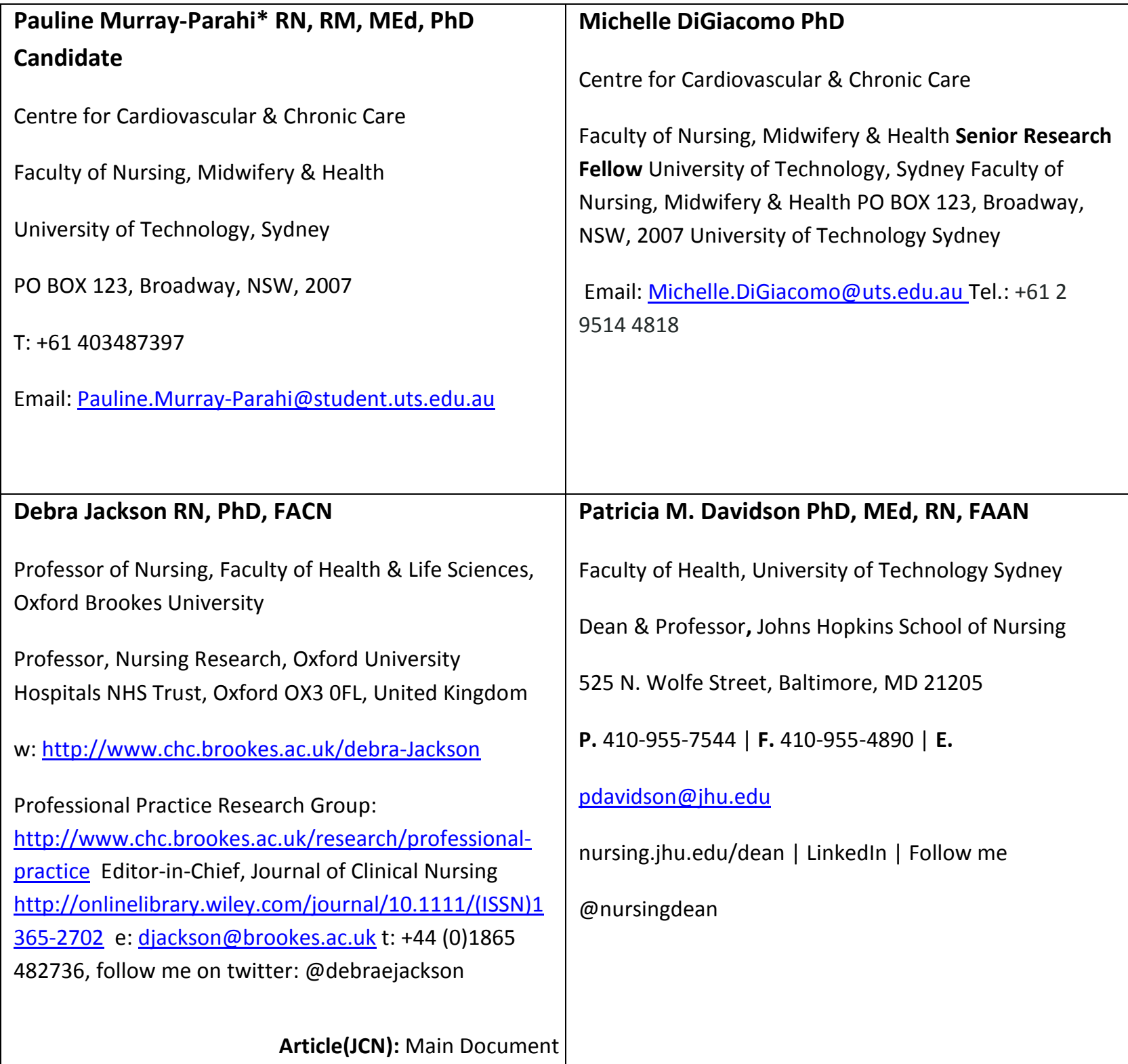




\title{
New Graduate Registered Nurse Transition into Primary Health Care roles: An integrative literature review
}

\author{
Keywords: \\ New graduate, \\ Registered nurse, \\ Transition \\ Primary health care \\ Integrative review
}

Aims: The objective of this integrative literature review was to summarise the literature describing new graduate nurse transition to professional practice within the primary health care setting.

Background: There is a plethora of research literature spanning several decades about new graduate nurse (NGN) transition in the acute care setting. Yet the experiences of NGN in the primary health care $(\mathrm{PHC})$ setting is unremarkable particularly considering the increasing demand for skilled health care workers and focus of health reform to provide care where people work and live.

Design: Electronic data bases, Academic Search Complete, EBSCO, Medline, PsycINFO, CINHAL, and ERIC were searched using a combination of terms and synonyms arising from three key concepts which identify the phenomenon; 'transition', 'new graduate registered nurse' and 'primary health care. An inclusive search strategy placed no limits on language or publication date.

Results: Of the fifty articles located and examined for relevance; 40 were sourced through databases and 10 from Google Scholar/Alerts and hand-searching references. None of the nineteen articles included addressed all key concepts.

Conclusions: Some challenges of researching the professional transition of graduate nurses in primary health care (PHC) settings included, an absence of definitive transition models, a dearth of literature and deference to acute care research.

Relevance to clinical practice: Nursing in PHC settings, particularly the client's home is notably different to hospital settings because of higher levels of isolation and autonomy. Societal changes, health reform and subsequent demand for skilled workers in PHC settings has caused health care providers to question the logic that such roles are only for experienced nurses. Implications arise for education and health service providers who desire to close the theory practice gap and mitigate risk for all stakeholders when next generation nurses have limited opportunities to experience PHC roles as undergraduates and newly graduated registered nurses are already transitioning in PHC. 


\section{What is known about this topic?}

- Transition to practice occurs over time

- The transition of new graduate registered nurses to professional practice is challenging

- New graduate nurse attrition challenges workforce models

\section{What this paper adds to clinical nursing globally}

- New graduate transition in primary health care is poorly defined in the literature

- There is a lack of clarity and differentiation between primary care and PHC. This ambiguity extends to nursing roles and setting, including facility based and home based PHC nursing roles. Our findings suggest a simple reference to nurses in this setting, as PHC nurses. Apart from accepted nomenclature if further differentiation is required this might be achieved by determining type and of PHC provided by these roles as selective or comprehensive

- In the context of global health care reform, further research and evaluation of new graduate nurse transition to practice programs in the PHC setting is needed

\section{Introduction}

Globally, transition to practice from the education setting is well recognised as a challenge for nurses (Flinkman et al. 2013). Barriers to transition are likely underscored in the primary health care setting where there has been significantly less research or literary attention.

In Australia almost $90 \%$ of people already use some form of PHC service annually (Carey et al. 2013). In an attempt to curb soaring health costs, meet the health care demands of an ageing community and address the increasing burden of chronic disease health reform has re-focused on primary health care $(\mathrm{PHC})$ as a means to shift care from overburdened hospital systems to the community and home setting. Referred to elsewhere as the perfect storm (Shur Coyle 2011), these and other societal changes have universally increased the demand and complexity of health care, and continue to alter workforce capacity. This shift in care delivery which has been expedited by medical advances and technological developments such as keyhole surgery (Hallett et al. 2012) have seen earlier hospital discharges of post operative patients and increasingly complex care and conditions managed in these settings. This level of care requires a highly skilled and practice-ready nursing workforce (Wolff et al. 2010). There are implications for the preparation and integration of the next generation of nurses who are currently, yet silently transitioning into professional practice within the PHC setting.

\section{Nursing roles in Primary Health care settings}

Community nursing is well established and has a long history internationally (Buhler-Wilkerson 2003, Ellefsen 2001, Howse 2007, Peter 2002). Meagher-Stewart (2001) and others describe community health nursing as an umbrella term which includes several specific areas of nursing in the community setting, each as a specialized field of practice i.e. public health nursing, home health nursing, nurse practitioner...(Craig \& Smith 1998, Jarvis 1981, King et al. 1994, Meagher-Stewart 2001). Although the role has undergone some changes over the years, it has long been considered the domain of only experienced nurses because of the level autonomy and isolation inherent in the role (Kemp et al. 2002). Predominantly registered nurses (RN), community nurses have traditionally practised 
within a comprehensive PHC paradigm, yet as a result of shifting care have had to reskill and balance the competing demands of their PHC ideals and the reality of post-acute care workloads, redefining their roles and role identity in the process (Hallett et al. 2012).

\section{Primary Health Care or Primary Care}

'Primary Care' is often referred to in the literature as 'primary health care', or the terms are used interchangeably which might explain why PHC may be enacted differently between location and jurisdiction. Internationally there is also ambiguity in the nomenclature of nursing in primary care (Freund et al. 2014). Primary care is by definition the first point of care; this is often the general practitioner (GP) or general practice nurse. Primary care incorporates some PHC principles and strategies such as disease prevention and health promotion (Keleher 2001). However opportunities for comprehensive PHC in general practice or indeed advancement for general practice nurses have been limited because of funding arrangements which have been skewed towards primary care services (Henderson et al. 2013)and tend to offer what may be referred to as selective PHC (Rifkin \& Walt 1986).

Primary health care (PHC) is a holistic and comprehensive view of health care, referred to as the ideal model of health care. In 1978 a charter of ten declarative statements was proposed at the Declaration of Alma Ata, providing a new definition of health and an inclusive paradigm of healthcare (WHO 1978b). PHC proposes that health is for all people, defining this as a state of complete physical, mental and social wellbeing and recognises the rights of individuals and the responsibilities of society and governments to commit to PHC, which essentially urges them to spend less on war and more on health (WHO 1978b). Primary Health Care principles are firmly rooted in the ideals of social justice, access and equity, sustainability, self-reliance, self-determination and cost effective health service provision close to where people work and live (WHO 1978a). However PHC is not inexpensive; it requires significant investment, yet is more cost effective than other alternatives. These principles need to be at the core of any future health care planning to achieve comprehensive PHC (ANF 2009, WHO 2008).

The overall aim of contemporary health policy on the other hand has been to reduce the cost of the growing burden of chronic disease and an ageing population by reducing length of stay, preventing unnecessary hospital admissions and keeping people living in their homes longer, and as independently as possible (DoHWS 2010). While the debate continues about how PHC should be interpreted in light of health reforms, there has been an undeniable and significant shift in the delivery of care as a result of these policies. Health care once previously confined to the acute care environment is now provided where people live and work and the demand for these services is growing along with the need for a highly skilled and practice-ready nursing workforce.

\section{Workforce supply and demand}

As this scenario unfolds, the nursing workforce is also changing. The majority of the nursing workforce is comprise of RNs; almost two thirds work in the acute care setting, although numbers of nurses employed in the tertiary healthcare setting is reducing over time (AlHW 2012). Conversely the number of nurses employed in the PHC setting is growing (HWA 2013, Kovner et al. 2014). In primary care teams nurses also represent the major non-physician workforce in the US, Canada, Australia, UK and the Netherlands (Freund et al. 2014). While the bulk of nurses working in PHC roles in Australia are employed as community nurses within the public sector $(14,000)$, the majority of 
growth has been noted in the private sector with employment of practice nurses $(11,000)$ in primary care roles (AlHW 2013).

Almost $40 \%$ of nurses are aged over 50 years and the average age of nurses is increasing over time (AlHW 2013). Four in five (80\%) of practice nurses are aged over 40 years and most of these are in their fifties (Bell 2013), making baby boomers the largest generational cohort in the nursing workforce. Despite concerted efforts to mitigate the anticipated skills shortage as a result of the eventual retirement of this group (Thomas et al. 2013), it is predicted there will still be a shortfall of 109,000 nurses between 2016 and 2025 (AlHW 2013, HWA 2013) requiring an additional 10,949 (Registered and Enrolled Nurse) graduates each year to meet demand (Mason 2013). This event will also signals the departure of some of the most experienced nurses in the workforce and this loss in capacity will likely cause a significant ripple effect in terms of both the preparation of undergraduate nurses (UGN) and the support of new graduate registered nurses as they transition to professional practice.

\section{New Graduate Nurse Transition}

Transition to professional practice is both an exhilarating and daunting prospect for any new graduate. Transition is both a process and an outcome (Chick \& Meleis 1986) as the process (of transition) occurs over time yet is time limited, so has an end product or outcome. Arguably all stakeholders in new graduate transition are affected to some degree by this process and are therefore invested in the outcome.

The period of professional transition for new graduate nurses may commence in the final semester of the undergraduate period (pre-registration) (Brooks \& Rojahn 2011) or completion of a three year undergraduate nursing degree at the commencement of nurse registration. This first year of practice is seen as a rite of passage into the profession (Jewell 2013). However, the key issue of transition is not when it occurs, but rather that it "...is a guided, dependant, situated learning [experience] and cognitive apprenticeship in a real-life setting" (Kramer et al. 2013). The importance of providing support to nurses during this period is undisputed and widely acknowledged in the international literature as key to the successful integration of the new graduate nurse into the profession (Blanzola et al. 2004, Owens 2013, Scott et al. 2008).

The knowledge generated from new graduate nurse transition research in the acute setting has resulted in the development and ubiquity of hospital-based transition to practice programs (TPP) and residency programs (Haggerty et al. 2013). These 1-2 year programs tend to be well-structured and are designed to ease this crucial period of adjustment to professional practice. Most include an induction or orientation period and almost universally involve some form of preceptorship (Rush et al. 2013). According to one systematic review there is strong evidence that a period of supportive and structured preceptorship benefits the newly qualified nurse and consequently improves recruitment and retention (Whitehead et al. 2013). Yet despite TTP programs being existence for many years (Schempp \& Rompre 1986), support is variable and best practice guidelines are limited by an overall low quality evidence (Levett-Jones 2005).

Reality shock (Kramer 1974), bullying and even horizontal violence (Clare \& Loon 2003, Salt et al. 2008) and eventual burnout (Rydon et al. 2008) continue to be reported as antecedents to intention to leave the profession (Kutney-Lee et al. 2013). Intention to leave and burnout, often precursors to their actual separation from the workforce (Flinkman et al. 2013), typically occur during the process of transition and integration into nursing practice when NGN are often stretched to their limit and at their most vulnerable (Parker et al. 2012). NGN separation not only represents a great loss to the fledgling professional it also negatively impacts workplace morale (Hillman and Foster, 2011) and 
places a burden on the organisation who may incur costs of between $\$ 100,000$ (Cubit \& Ryan 2011, El Haddad et al. 2013) and $\$ 145,000$ (Thomas et al. 2013) to replace a new graduate nurse. These events have also been linked with poor patient outcomes (Booker 2011), which as we know may have tragic consequences for the consumer and the community. While the salient issues in terms of successful professional transition and integration are increased independence (Maxwell et al. 2011, Sargent \& Olmedo 2013) and confidence in the role (Craig et al. 2012), the safety of all stakeholders including, the consumer, the nurse, and the organisation should also be a priority.

\section{New Graduate Nurse Transition to PHC Roles}

For nurses, the process of professional transition begins before registration during the undergraduate period. However there are concerns contemporary undergraduate nurse (UGN) curricula may not provide sufficient PHC content and their exposure to authentic PHC nursing roles outside the acute care/hospital setting as UGN can be limited and patchy (Keleher et al. 2010). As the increasing demand for skilled nurses in PHC settings continue and the predicted undersupply of nurses occurs, the presence of new graduate nurses in this setting will likely become commonplace since they represent the largest pool of future recruits (HWA 2013, Wells \& Ellis 2010). However nursing roles in PHC are still relatively uncharted in terms of research literature, and the studies that are available almost invariably defer to NGN transition research in the acute care setting. What this literature clearly tells us is that while transition to practice can be an exciting time, it can also be the most stressful and tumultuous period in a new nurse's career (Parker et al. 2012) taking as long as 12 months for the new graduate to feel confident (Casey \& Fink 2004)even in familiar settings like acute care .

Roles like the community nurse (CN) have long been considered the domain of experienced nurses and have practiced within a case management model of care which differ from the acute care experience where team nursing or patient allocation are the typical paradigms (Fernandez et al. 2012). Case managers assume much of the responsibility for the follow up and coordination of care and take on the mantle of patient advocate (Lee et al. 1998). Regardless of care model, the community nurse role still provides a variety of nursing activities and can involve performing complex procedures in isolation within a client's home. These responsibilities suggest a level of personal accountability and autonomy which even highly skilled, senior nurses in the acute care setting may not experience nor indeed care to experience. Yet this notion of autonomy arises in the literature as a key feature of the $\mathrm{CN}$ role and may explain the pervasive yet unchallenged assumption that community nursing is simply the domain of experienced practitioners (Kemp et al. 2005). However autonomy is also linked with satisfaction, retention and safety in some workforce and new graduate transition studies (Altier \& Krsek 2006, Kramer et al. 2013) and so might actually be used as an incentive to recruit to areas like PHC. However there is a general lack of clarity about the nurse role in PHC, what they do (Brookes et al. 2004, Mckenna et al. 2014) or indeed how much the role has changed over the years (Hallett et al. 2012). Although new graduate nurses have been transitioning into the PHC space and Community Nurse $(\mathrm{CN})$ role for some time, the contemporary literature has remained silent about this phenomenon despite considerable growth in this area. These issues and the questions they provoke are complex and possibly disturbing for some. This paper attempts to provide some clarity and direction for future research. 
The purpose of this review was to summarise the literature on new graduate nurse transition in PHC and gain a greater understanding by identifying the key issues, highlighting the challenges of researching nurse transition in the PHC setting, any gaps in the literature and implications for future research.

\section{Method}

Three key concepts of interest that were pursued as lines of enquiry in the following review include transition,; the new graduate registered nurse, the protagonist or subject undergoing transition; and primary health care (PHC), the context or environment in which this transition occurs.

An integrative literature review was undertaken to gain an understanding of these key concepts and to highlight any gaps in the literature. Such reviews are informative where the phenomenon is new or where there is limited research available and constitute the broadest type of literature review (Whittemore \& Knafl 2005). Integrative literature reviews are considered primary research since it demands the same level of rigor and offers high level evidence (Evans \& Pearson 2001). The varied sampling frame provided by this method also allows for the integration of experimental, nonexperimental empirical and theoretical data and can incorporate a wide range of purposes (Whittemore \& Knafl 2005) including the synthesis of separate empirical findings into a coherent whole (Cooper 1982). There are essentially 6 tasks involved in the process which represent the characteristics of primary research, including identifying the issues in question or developing a hypothesis problem, sampling and the analysis, interpretation and reporting of findings (Ganong 1987).

\section{Search strategy and selection criteria}

The process involved undertaking a comprehensive database search that included; Academic Search Complete, EBSCO, Medline, PsycINFO, CINHAL, and ERIC (Education Resource) and was carried out during November 2013 - April 2014. Key words and synonyms of; transition, professional transition, new graduate, nurse, primary health care, primary care, community nurse using truncation and format peculiar to each major data base were also used to capture all relevant articles, as well as a search of the reference lists in the articles retrieved. In addition to the major database searches a RSS (Really Simple Syndication) feed was setup with Google Scholar Alerts, this combined with hand searching journals and reference lists led to the discovery of ten $(n=10)$ additional references related to nursing transition to the $\mathrm{PHC} /$ home setting.

A total of fifty articles were located from all sources. Abstracts and titles were reviewed for relevance to the phenomenon based on the three key concepts, duplicates and irrelevant articles were removed and the remaining nineteen articles were reviewed in detail (Tables $1 \& 2$ ). The process from search to inclusion is outlined in figure 1.

\section{Insert Figure 1. About here}

\section{Analysis Methods}

The aims of the review were to set the scene of new graduate nurse transition in PHC and gain a greater understanding of the phenomenon. Synthesis of literature was facilitated through the use of various tools used to store, categorise, interpret, analyse and synthesise the articles retrieved. In light of the limited search results and preliminary analysis revealing none of the articles identified 
specifically addressed all key concepts, a decision was made to differentiate rather than exclude articles.

In keeping with the aims of the review process data were categorised by a) total number of concepts identified and b) quality of evidence. Depending on quality of evidence, articles were either classified under first or second order inclusion criteria. Those articles meeting first order criteria, contained a minimum of two key concepts and one minor concept and was original research or reported on original research. Using the elements of this data set as an integrated source covered the key concepts of the transition of new graduate nurses and PHC/community and the remaining articles contributed to the overall synthesis. These are presented in the same table as first order articles but shaded to differentiate these data (Table 2.).

A matrix was developed over several iterations during the synthesis process and categories emerged as elements were identified. These data were initially classified by 'author and year', 'country' and because of the merging of PHC and primary care terminology in the literature, key concepts were expanded to include 'primary care' and 'other' i.e. models or transition program. Using the matrix checklist following 'key concepts', 'roles' were included due to the heterogeneous sample arising from 5 countries with diverse nomenclature. This included, number of 'databases' \& inclusion of relevant 'references' and/or whether this included a literature review. Categories including; 'Methodology/Theory', 'Report/Description/Findings', 'Recommendations and/or Significance', made up the free text portion of the table and remainder of the tool.

The level of evidence, determined by the quality of research, used a similar scoring technique as Rush et al (2013), developed by Beck (2001) and adapted by Park and Jones (2010). This included the measurement of 3 criteria; 1) study design, 2) sample size and 3) author expertise. The scale, which allowed for a minimum total score of 3 to a maximum of 8 , was determined by level of quality in each of these criteria [see table legend for details] (Beck 2001, Park \& Jones 2010, Rush et al. 2013)Since most research articles incorporated interviews and/or focus groups as part of their research strategy, the process was also guided by COREQ (Consolidated criteria for reporting quality research), a 32 item checklist used for assessing and reporting qualitative research, specifically interviews and focus groups (Tong et al. 2007). The quality of literature reviews ( $n=2$ ) was assessed using a critical review checklist (Monash 2014) with similar features to tools used in Critical Appraisal Skills Program (CASP 2014. )

\section{Results}

Fifty $(n=50)$ articles were located in the review process and nineteen $(n=19)$ were retained for further analysis, tables 1 and 2 summarise those articles. The majority of these articles originated from North America ( $n=9)$, Australia $(n=5)$, UK $(n=2)$, Norway $(n=1)$, Saudi Arabia $(n=1)$ and South Africa $(n=1)$. Nomenclature and roles within various locations and jurisdictions were diverse, as one might expect from a heterogonous sample. None of the articles addressed all three key concepts; 1 ) Transition, 2) New Graduate Nurse and 3) Primary Health Care, but did provide some insight into the phenomenon of new graduate nurse transition to professional practice in the PHC setting. Most articles identified the gap about the phenomenon in the research literature and recognised the absence of best practice guidelines for transition in this setting.

\section{Study Characteristics}

According to NHMRC criteria, the level of evidence generated by each of these studies would be considered of low evidence. Apart from one mixed methods study $(n=1)$, the studies used qualitative 
methods $(n=18)$ which either were reports of original research or discussion papers which proposed transition or internship programs/models in the (Gordon et al. 2014). Some research did however outline the lived experiences of new graduate nurse and even experienced nurses undergoing professional transition in the PHC setting. This evidence was primarily achieved through interviews (Roziers et al. 2014, Sneltvedt et al. 2010) and/or focus groups (Ellis \& Chater 2012, Roziers et al. 2014). Studies, including literature reviews varied in sample sizes (range $2-35$ ) participants/articles.

Impact

Insert Table $1 \&$ Table 2. about here

The impact of transition in the PHC setting is hard to define in the absence of empirical data. However the studies included in this integrative literature review, which invariably defer to acute care research in an attempt to fill this void, clearly demonstrate the effects of poor transition experiences and the serious implications for the neophyte professional, the profession, the consumer - indeed all stakeholders. The available literature in PHC does point to the differences between the two settings (Al-Mazrooa 2011) (Table 2.) and calls for a model or program specifically designed to meet the needs of new graduate nurse undergoing transition to this evolving and complex health care environment.

\section{Discussion}

The preceding literature review demonstrated a gap in contemporary literature regarding the professional transition experiences of new graduate nurses into the PHC setting and a clear deference to research in the acute care setting. In contrast to the acute care literature which is replete with research outlining the barriers and facilitators of new graduate nurse transition, PHC literature is lacking (Freeling \& Parker 2014), and for that reason comparison between settings was understandably challenging. Even those articles based on a broad interpretation of the key concepts included in this review still did not adequately address the phenomenon of new graduate nurse transition in the PHC setting. The focus of these enquiries either refer to the transition of experienced nurses from the familiar acute care environment into unfamiliar community nurse roles (Ellis \& Chater 2012) or new graduate nurse practising in facility-based community settings (Dyess \& Sherman 2009) (Sargent \& Olmedo 2013) rather than discussing the unique experiences of professional nursing transition in the home environment.

The former study suggests a parallel between the professional transition of new graduate nurse in the acute care setting and that of experienced acute care nurse transition to unfamiliar settings like PHC (Ellis \& Chater 2012). While the authors do not explicitly include new graduate nurses, the study offers another line of enquiry that likens the experiences of new graduate nurse transition in the acute setting to experienced acute care nurses transitioning to PHC settings. The suggestion that transition experiences particularly in unfamiliar roles or environments like PHC can be as dislocating as a lack of experience highlight the unique considerations for new graduate nurse undergoing transition in these settings who may have to contend with both challenges. However one study, a descriptive report published over 16 years ago did discuss the new graduate nurse perspective in a more optimistic light, noting even though participants $(n=2)$ had no experience, 'without the usual 12 month acute care post graduate period' NGNs still transitioned successfully (Gavin et al. 1996).

Most articles acknowledged the lack of research and uniqueness of nursing roles in the PHC setting yet continue to defer to readily available research and knowledge nursing transition in the acute care area. However the need for guidelines and models specifically for nurses transitioning into roles 
in the PHC and community setting was widely recognised. This notion of practice setting or environment is an important point of distinction because it provides the context, differentiating where rather than what nursing services are provided since these services increasingly involve the sort of procedures and care once only provided in high acuity areas of the tertiary setting. Unlike acute care settings or even facilities located within the community setting, the home environment is arguably the least discussed site of care in research literature. Table 3 outlines some points of differentiation.

Insert Table 3. about here

The available knowledge of the nurse's role in this environment suggests a high level of autonomy and isolation (Maxwell et al. 2011) that even veteran nurses in the acute care setting would not normally experience. This gap in the research literature has significant implications for new graduate nurses in transition and those involved in the preparation, facilitation and evaluation of their transition within this setting since the client's home aptly represents both an unfamiliar and unpredictable practice setting. This context or setting also raises the question of supervision and may even allude to the level of risk to which the stakeholders are exposed and the possible risk management of new graduate nurses currently undergoing transition in these settings.

\section{Best Practice Guidelines and Models of Transition in PHC}

Application of best practice guidelines mitigates risk for all stakeholders, yet the articles analysed in this review provided no definitive guidelines to successful transition, best practice or otherwise which consider the unique transition of new graduate nurse in PHC, particularly in the home environment. On the other hand even data available from the comparatively well researched acute care setting has been reported to lack the quality of evidence required to offer precise components, objective measurement (Freeling \& Parker 2014)or best practices recommendations (Rush et al. 2013).

\section{Preparation and Work Readiness}

UGN preparation and degree of work-readiness for nursing roles in the acute care setting remains a source of contention, but is particularly questionable in the PHC setting when undergraduate clinical experience in this environment is already considered patchy (Keleher 2001) and research literature scarce. While undergraduate employment choices may have not traditionally extended to primary health care (Happell 1998) and limited clinical experiences or knowledge of PHC may account for this, but a recent study in the US noted an interesting shift away from hospital employment choices and although there were no figures reporting a move of new graduate nurses towards primary care they suggest this may present opportunity for the expanding community and primary care setting (Kovner et al. 2014). However the question of work-readiness like transition programs is variable according to the abundant literature arising from the acute care setting which clearly recognising the first year of practice as a crucial period in the nurse's career, yet contemporary PHC literature remains comparatively silent about this new graduate nursing rite of passage.

How can this be? If the first year of professional nursing practice is indeed such a crucial period in arguably controlled environments like hospitals, one might question if there shouldn't be equal if not more scrutiny of new graduate nurse transition and preparation for practice in the home care setting? While at least one study, suggests new graduate nurse can thrive in both role and 
environment (Gavin et al. 1996), relative to the exponential growth and demand in the PHC setting, there still clearly exists a surprising gap in the PHC research literature about this phenomenon.

\section{Study limitations and strengths}

The inclusive search criteria used in this review was deliberate in view of the dearth of research. While this resulted in a heterogeneous sample the results, it also clearly demonstrated some consistencies; the most conspicuous was the dominance of primary care within the available PHC literature. While all 212,281 articles resulting from an initial search of both terms could not be reviewed, primary care is simply researched more often than PHC (see figure 2). Despite making a deliberate reference to 'primary health care' as a key word search term or filter, subject content often included 'primary care' as a subheading or even became the main focus of the article, supporting Keleher's assertion that these terms are often used interchangeably (Keleher 2001). In the final analysis, key concepts were relaxed to allow the inclusion of 'primary care', since the holistic notion of PHC in terms of context and setting justifies this inclusion.

This is consistent with the aims of this integrated literature review which was to explore the phenomenon of new graduate nurse transition in the PHC environment - however that is interpreted or enacted. Analysis of the articles reviewed also demonstrated a merging of terminology and deference to primary care. One article, an opinion piece supporting new graduate nurse transition programs as a strategy for building a sustainable PHC nursing workforce, almost exclusively discussed practice nurses as the PHC workforce, referring to them as PHC nurses who work in general practice (Gordon et al. 2014). While the authors' assertion that practice nurses are PHC nurses is not disputed here, as other writers in PHC have noted there tends to be limited discussion of the remaining PHC nursing workforce including roles like the community nurse (Henderson et al. 2013, Keleher et al. 2007). This omission has a tendency to exclude the experiences and voices of a large proportion of the PHC workforce who provide comprehensive PHC and are key stakeholders in the safe and successful transition of new graduates in that setting.

\section{Conclusion}

The issues driving reform are complex but have created a significant shift from hospital to community based care delivery. Novice nurses transitioning into this challenging environment add yet another dimension of complexity and even potential risk, particularly in roles where care occurs alone, in the client's home.

Further research into new graduate nurse transition in the PHC is needed, especially within this environment to explore the unique experiences of newly graduated registered nurses in these roles and diverse settings will provide some insight into their safety, competence and requirements as emerging professionals. This evidence will be able to inform future transition to practice, wherever this occurs. Best practice guidelines and objective measurement of successful new graduate nurse transition are required in both the PHC and acute care settings. In the absence of empirical evidence, existing acute care models of transition have been adapted into the PHC setting but given the research limitations and differences in practice environments, these 'off-the-rack' strategies may at best only provide a generic guide for transition until this phenomenon is adequately researched. Perhaps applying the PHC principles of holism, inclusion and connection may even provide the framework to unpack these complex issues and answer the question of how best to prepare and support the next generation of nursing professionals transitioning to emerging roles in this unique environment. It is imperative new graduate nurses are prepared for roles in environments like the 
home setting where resources are limited and yet more complex care is now provided. The workreadiness of new graduate nurses particularly in comparatively uncharted and complex environments like PHC will be a distinct advantage for all stakeholders.

\section{Conflict of interest}

None declared.

\section{Contributors}

New Graduate Transition to PHC roles conceived by PMP and PMD. PMP, MD, DJ and PMD developed the manuscript focus and PMP wrote the initial manuscript. All authors critically revised the manuscript. All authors read and approved the final manuscript.

\section{Acknowledgements}

Jane Van Balen, health research librarian at University of Technology Sydney who provided expert advice on relevant databases and search strategy. 


\section{References}

AlHW (2012) Nursing and midwifery workforce 2011. Australian Institute of Health and Welfare, Canberra.

AlHW (2013) Nursing and midwifery workforce 2012, Canberra: AlHW.

Al-Mazrooa AA (2011): Evolving Nurses into Home Health Care Practice. Home Health Care Management \& Practice 23, 118-124.

Altier ME \& Krsek CA (2006): Effects of a 1-year residency program on job satisfaction and retention of new graduate nurses. Journal for Nurses in Staff Development 22, 70-77.

ANF ANF (2009) Primary Health Care in Australia. Australian Nursing Federation, Sydney, p. 71.

Beck CT (2001): Predictors of postpartum depression: an update. Nursing Research 50, 275-285.

Bell K (2013): In practice, nurses offer a healthier future for primary care. Health Voices, 8.

Blanzola C, Lindeman R \& King ML (2004): Nurse internship pathway to clinical comfort, confidence, and competency. Journal for nurses in staff development : JNSD : official journal of the National Nursing Staff Development Organization 20, 27-37.

Booker CA (2011) An Exploration of Factors that influence End of Career Nurses' Decision Making regarding their Workforce Participation. Australian Catholic University.

Brookes K, Davidson PM, Daly J \& Hancock K (2004): Community health nursing in Australia: a critical literature review and implications for professional development. Contemporary Nurse 16, 195-207.

Brooks N \& Rojahn R (2011): Improving the quality of community placements for nursing students. Nursing Standard 25, 42-47.

Buhler-Wilkerson K (2003) No place like home: A history of nursing and home care in the United States. JHU Press.

Carey T, Wakerman J, Humphreys J, Buykx P \& Lindeman M (2013): What primary health care services should residents of rural and remote Australia be able to access? A systematic review of "core" primary health care services. BMC Health Services Research 13, 178.

Casey K \& Fink R (2004): The graduate nurse experience. Journal of Nursing Administration 34, 303.

CASP CASP (2014. ) Critical Appraisal Skills Programme (CASP): CASP Checklists CASP UK, Oxford UK. Available at: http://www.casp-uk.net/\#!casp-tools-checklists/c18f8 (accessed 28/12/2014 2014).

Chick N \& Meleis Al (1986): Transitions: A nursing concern. School of Nursing Departmental Papers, 9.

Clare J \& Loon Av (2003): Best practice principles for the transition from student to registered nurse. Collegian: Journal of the Royal College of Nursing Australia 10, 25-31.

Cooper HM (1982): Scientific guidelines for conducting integrative research reviews. Review of educational research 52, 291-302.

Craig C, Moscato S \& Moyce S (2012): New BSN Nurses' Perspectives on the Transition to Practice in Changing Economic Times. Journal of Nursing Administration 42, 202-207.

Craig PM \& Smith LN (1998): Health visiting and public health: back to our roots or a new branch? Health \& Social Care in the Community 6, 172-180.

Cubit KA \& Ryan B (2011): Tailoring a Graduate Nurse Program to meet the needs of our next generation nurses. Nurse Education Today 31, 65-71.

DoHWS (2010) Department of Health Workforce Statistics

Dyess SM \& Sherman RO (2009): The first year of practice: New graduate nurses' transition and learning needs. The Journal of Continuing Education in Nursing 40, 403.

El Haddad M, Moxham L \& Broadbent M (2013): Graduate registered nurse practice readiness in the Australian context: An issue worthy of discussion. Collegian 20, 233-238.

Ellefsen B (2001): Changes in health visitors' work. Journal of Advanced Nursing 34, 346-355.

Ellis I \& Chater K (2012): Practice protocol: Transition to community nursing practice revisited. Contemporary Nurse: A Journal for the Australian Nursing Profession 42, 90-96.

Evans D \& Pearson A (2001): Systematic reviews: gatekeepers of nursing knowledge. Journal of Clinical Nursing 10, 593-599. 
Fernandez R, Johnson M, Tran DT \& Miranda C (2012): Models of care in nursing: a systematic review. International Journal of Evidence-Based Healthcare 10, 324-337.

Flinkman M, Leino-Kilpi H \& Salantera S (2013): Nurses' intention to leave the profession: integrative review. J Adv Nurs 66, 1422-1434.

Freeling M \& Parker S (2014): Exploring experienced nurses' attitudes, views and expectations of new graduate nurses: A critical review. Nurse Education Today.

Freund T, Everett C, Griffiths P, Hudon C, Naccarella L \& Laurant M (2014): Skill mix, roles and remuneration in the primary care workforce: who are the healthcare professionals in the primary care teams across the world? International Journal of Nursing Studies.

Ganong LH (1987): Integrative reviews of nursing research. Research in nursing \& health 10, 1-11.

Gavin MJ, Haas LJ, Pendleton PB, Street JW \& Wormald A (1996): Orienting a new graduate nurse to home healthcare. Home Healthcare Nurse 14, 381-387.

Gordon CJ, Aggar C, Williams AM, Walker L, Willcock SM \& Bloomfield J (2014): A transition program to primary health care for new graduate nurses: a strategy towards building a sustainable primary health care nurse workforce? BMC Nursing 13, 34.

Haggerty C, Holloway K \& Wilson D (2013): How to grow our own: An evaluation of preceptorship in New Zealand graduate nurse programmes. Contemporary Nurse: A Journal for the Australian Nursing Profession 43, 162-171.

Hallett CE, Madsen W, Pateman B \& Bradshaw J (2012): "Time Enough! or Not Enough Time!" An Oral History Investigation of Some British and Australian Community Nurses' Responses to Demands for "Efficiency" in Health Care, 1960-2000. Nursing History Review 20, 136-161.

Happell B (1998): Student nurses' attitudes toward a career in community health. Journal of Community Health 23, 269-279.

Henderson J, Koehne K, Verrall C, Gebbie K \& Fuller J (2013): How is Primary Health Care conceptualised in nursing in Australia? A review of the literature. Health \& Social Care in the Community.

Howse C (2007): " The ultimate destination of all nursing": the development of district nursing in England, 1880-1925. Nursing history review: official journal of the American Association for the History of Nursing 15, 65.

HWA (2013): Health Workforce Australia [2013]: Health Workforce by Numbers - Issue 2.

Jarvis LL (1981): Community health nursing: Keeping the public healthy. AJN The American Journal of Nursing 81, 1394.

Jewell A (2013): Supporting the novice nurse to fly: A literature review. Nurse Education in Practice 13, 323-327.

Keleher $\mathrm{H}$ (2001): Why primary health care offers a more comprehensive approach to tackling health inequities than primary care. Aus J Prim Health 7, 57 - 61.

Keleher H, Parker R, Abdulwadud O, Francis K, Segal L \& Dalziel K (2007): Review of Primary and Community Care Nursing.

Keleher H, Parker R \& Francis K (2010): Preparing nurses for primary health care futures: how well do Australian nursing courses perform? Australian Journal of Primary Health 16, 211-216.

Kemp L, Comino E, Harris E \& Killian D (2002): A decade of change in a community health service: a shift to acute and short-term care. Australian Health Review 25, 148-155.

Kemp LA, Harris E \& Comino EJ (2005): Changes in community nursing in Australia: 1995-2000. Journal of Advanced Nursing 49, 307-314.

King ME, Harrison MJ \& Reutter L (1994): Public health nursing or community health nursing: examining the debate. Canadian journal of public health= Revue canadienne de sante publique 86, 24-25.

Kovner CT, Brewer CS, Fatehi F \& Katigbak C (2014): Original Research: Changing Trends in Newly Licensed RNs. AJN The American Journal of Nursing 114, 26-34.

Kramer M (1974) Reality shock: Why nurses leave nursing. Mosby St. Lonis.

Kramer M, Maguire P, Halfer D, Brewer B \& Schmalenberg C (2013): Impact of Residency Programs on Professional Socialization of Newly Licensed Registered Nurses. Western Journal of Nursing Research 35, 459-496. 
Kutney-Lee A, Wu ES, Sloane DM \& Aiken LH (2013): Changes in hospital nurse work environments and nurse job outcomes: An analysis of panel data. International Journal of Nursing Studies 50, 195-201.

Lee DT, Mackenzie AE, Dudley-Brown S \& Chin T (1998): Case management: a review of the definitions and practices. Journal of Advanced Nursing 27, 933-939.

Levett-Jones T (2005): A review of graduate nurse transition programs in Australia. The Australian journal of advanced nursing 23, 40-45.

Mason J (2013): Review of Australian Government health workforce programs. Canberra: Department of Health and Ageing (Australian Government).

Maxwell C, Brigham L, Logan J \& Smith A (2011): Challenges facing newly qualified community nurses: a qualitative study. British Journal of Community Nursing 16.

Mckenna L, Parry A, Kirby C, Gilbert K \& Griffiths R (2014): Learning in primary health care settings: Australian undergraduate nursing students' perspectives. Journal of Nursing Education and Practice 4, p1.

Meagher-Stewart D (2001) Public Health Nurses'Community Development Practice with Women in High-Risk Environments. In Department of Curriculum, Teaching and Learning, University of Toronto, Ontario institute for Studies in Education, p. 395.

Monash U (2014) Research at Monash. Monash University Melbourne. Available at: http://artsonline.monash.edu.au/aallu/files/2013/03/critical-review-checklist.pdf (accessed 21/12/2014 2014).

Owens NG (2013): New graduate nurse preceptor program: A collaborative approach with academia. Journal of Nursing Education and Practice 3, p1.

Park M \& Jones CB (2010): A retention strategy for newly graduated nurses: an integrative review of orientation programs. Journal for Nurses in Professional Development 26, 142-149.

Parker V, Giles M, Lantry G \& McMillan M (2012): New graduate nurses' experiences in their first year of practice. Nurse Education Today 34, 150-156.

Peter E (2002): The history of nursing in the home: revealing the significance of place in the expression of moral agency. Nursing Inquiry 9, 65-72.

Rifkin S \& Walt G (1986): Why health improves: defining the issues concerning 'comprehensive primary health care' and 'selective primary health care'. Soc Sci Med 23, 559 - 566.

Roziers RL, Kyriacos U \& Ramugondo EL (2014): Newly Qualified South African Nurses' Lived Experience of the Transition From Student to Community Service Nurse: A Phenomenological Study. Journal of Continuing Education in Nursing 45, 91-100.

Rush KL, Adamack M, Gordon J, Lilly M \& Janke R (2013): Best practices of formal new graduate nurse transition programs: An integrative review. International Journal of Nursing Studies 50, 345-356.

Rydon SE, Rolleston A \& Mackie J (2008): Graduates and initial employment. Nurse Education Today 28, 610-619.

Salt J, Cummings GG \& Profetto-McGrath J (2008): Increasing retention of new graduate nurses: A systematic review of interventions by healthcare organizations. Journal of Nursing Administration 38, 287-296.

Sargent L \& Olmedo M (2013): Meeting the Needs of New-Graduate Nurse Practitioners. Journal of Nursing Administration 43, 603-610.

Schempp CM \& Rompre RM (1986): Transition Programs for New Graduates: How Effective Are They? Journal for Nurses in Professional Development 2, 150-156.

Scott ES, Keehner Engelke M \& Swanson M (2008): New graduate nurse transitioning: Necessary or nice? Applied Nursing Research 21, 75-83.

Shur Coyle J (2011): Development of a Model Home Health Nurse Internship Program for New Graduates: Key Lessons Learned. The Journal of Continuing Education in Nursing 42, 201214.

Sneltvedt T, Odland L-H \& Sørlie V (2010): Standing on one's own feet: New graduate nurses' home health care challenges and work experiences study. Home Health Care Management \& Practice 22, 262-268. 
Thomas L, Chaperon Y \& Federation AN (2013): Submission to the Health Workforce Australia consultation paper on Nursing Workforce Retention and Productivity. Canberra: Australian Nursing Federation.

Tong A, Sainsbury P \& Craig J (2007) Consolidated criteria for reporting qualitative research (COREQ): a 32-item checklist for interviews and focus groups.

Wells Y \& Ellis J (2010): Changes in the composition of the aged care workforce: Are they a good thing? Health Issues, 20.

Whitehead B, Owen P, Holmes D, Beddingham E, Simmons M, Henshaw L, Barton M \& Walker C (2013): Supporting newly qualified nurses in the UK: A systematic literature review. Nurse Education Today 33, 370-377.

Whittemore R \& Knafl K (2005): The integrative review: updated methodology. Journal of Advanced Nursing 52, 546-553.

WHO (1978a): International conference on primary health care. Alma-Ata, USSR Sept, 6 - 12.

WHO WHO (1978b): Primary health care: report of the International Conference on Primary Health Care, Alma-Ata, USSR, 6-12 September 1978/jointly sponsored by the World Health Organization and the United Nations Children's Fund.

WHO WHR (2008): Primary Health Care: now more than ever.

Wolff AC, Pesut B \& Regan S (2010): New graduate nurse practice readiness: Perspectives on the context shaping our understanding and expectations. Nurse Education Today 30, 187-191. 